\title{
Use of ultrasound for cleaning of components of historical vehicles in Technical Museum in Brno
}

Rapouch K., Mrázek M.

Technical Museum in Brno

E-mail: rapouch@technicalmuseum.cz

In the collections of Technical Museum in Brno, large number of historical vehicles is placed. During the operation, parts of their motors are being fouled. Frequently, they become even immobile (e. g. due to a fouled fuel system). In this case, the method using ultrasound with a suitable concentrate appears as the most suitable. In fact, ultrasound works also in inaccessible places with large efficiency. Not only the chosen solution influences the cleaning efficiency, but also parameters as time, bath temperature and ultrasound frequency. The cleaning process was evaluated according to the volume of removed dirt and by observing wettability change using the measuring of contact angle of a water drop. The ultrasound shock waves influence the surface to a certain extent also mechanically. That is why, the ultrasound effect on defects in the structure was observed. The aggressivity of cleaning concentrates was evaluated on the ground of determination of dissolved metals in the baths by ET AAS method.

\section{INTRODUCTION}

In the collections of Technical Museum in Brno, large number of historical motor vehicles is placed. There are personal cars, goods vehicles, or army vehicles and also city public transport vehicles. Based on the custodian's requirements, many of them were and will be put into operation. When intervening as a conserver-restorer, it is necessary to proceed according to the conserver's-restorer's principles, ethical rules, and international conventions inclusive Charter of Turin. A sensitive approach requires cleaning of various surfaces without mechanical taking of material. In fact, there are original traces of working or original production technology on many of them, e. g. casting into sand moulds and the like. These are mostly engine blocks, transmission gearboxes, axles, and steering parts. These exposed groups are to a large extent fouled by petroleum products mixed with dust and mud, the so-called daub. During mechanical removing as blast cleaning, grinding, or brushing, to varying degrees occurs an irreversible damage of the original features of manufacturing processes and surfaces. Chemical cleaning appears often as ineffective and can leave residues in microcracks. Over time, they can appear on the surface or they degrade the parent material. Especially when working with fuel system of historical vehicles, cleaning is the basic act for putting them into operation and their subsequent use. The basic element in the fuel system is carburettor. Its faultless adjustment requires completely clean nozzle passages. It is not possible to clean the narrow, long passages mechanically - ultrasound is thus a unique technology. $[1,4,5]$

\section{EXPERIMENT}

The testing of ultrasonic cleaning was carried out in such a way as to be similar to cleaning of real objects as much as possible. The main question was how to simulate the fouling on the samples. This problem is examined further in the paragraph Dirt. There are many factors which influence the efficiency of ultrasonic cleaning. Within this study, the following factors were chosen:

- Choice of cleaning concentrate

- Ultrasound frequency

- Time of cleaning

- Bath temperature

The conditions were reciprocally combined as to allow a comparison of the synergies of their effect. The description of the experiment process will be analysed in the following paragraphs.

\section{Cleaning solutions}

Within the testing of methods of ultrasonic cleaning, the efficiency of three selected cleaning baths with different $\mathrm{pH}$ values was evaluated. However, the $\mathrm{pH}$ value was higher than 7 . All the baths were mixed in the same concentration, which means $20 \%$. An overview of the solutions, their composition and $\mathrm{pH}$ are summarized in Table 1. 
Tab. 1. Overview of cleaning solutions

\begin{tabular}{|c|l|c|}
\hline Solution & \multicolumn{1}{|c|}{ Chemical composition } & $\begin{array}{c}\text { pH of } \\
\text { the 20\% } \\
\text { solution }\end{array}$ \\
\hline $\begin{array}{c}\text { Ag MAX } \\
\text { III }\end{array}$ & $\begin{array}{l}\text { triethanolamine, non-ionic surfactants, } \\
\text { propylene glycol } n \text {-butyl ether, mono- } \\
\text { potassium phosphate, potassium } \\
\text { silicate }\end{array}$ & 9.41 \\
\hline $\begin{array}{c}\text { Star } \\
\text { TN }\end{array}$ & $\begin{array}{l}\text { propylene glycol } n \text {-butyl ether, mono- } \\
\text { potassium phosphate, sodium silicate } \\
\text { pentahydrate, propyl heptanol } \\
\text { ethoxylate, alcohol } \mathrm{C}_{9}-\mathrm{C}_{11} \text { ethoxylated }\end{array}$ & 11.97 \\
\hline $\begin{array}{c}\text { Star } \\
\text { BS N }\end{array}$ & $\begin{array}{l}\text { ethoxylated and propoxylated alcohols } \\
\mathrm{C}_{8}-\mathrm{C}_{10}, \text { ethoxylated alcohols } \mathrm{C}_{9}-\mathrm{C}_{11}, \\
\text { caprylic acid, ethanolamine }\end{array}$ & 8.43 \\
\hline
\end{tabular}

\section{Sample coupons}

Aluminium sheet of $2 \mathrm{~mm}$ thickness was chosen as a material on which the cleaning was tested. According to an XRF analysis, it contained $99,3 \%$ of $\mathrm{Al}, 0,4 \%$ of $\mathrm{Fe}$, and $0,3 \%$ of $\mathrm{Si}$. Ten round coupons of a diameter of $2,5 \mathrm{~cm}$ with a drilled hole for hanging were made of this sheet. The surface of the samples was blasted with glass microbeads with a particle size of $150 \mu \mathrm{m}$.

\section{Impurities}

The fouling substance was chosen in such a way as to maximally simulate the real fouling of the components of motor vehicles. The originally intended use of clean oil or vaseline was abandoned. In fact, after a comparison with cleaning of real objects was made, the impurities were removed very quickly, thus it would not be possible to observe the impact of the solutions and the cleaning parameters. That is why, the impurities from a real object were taken, which contain particularly the solidified polluted oil and dust (Fig. 1). To obtain a homogeneous mixture, it was dissolved in a small amount of surgical spirit and filtered through a sieve

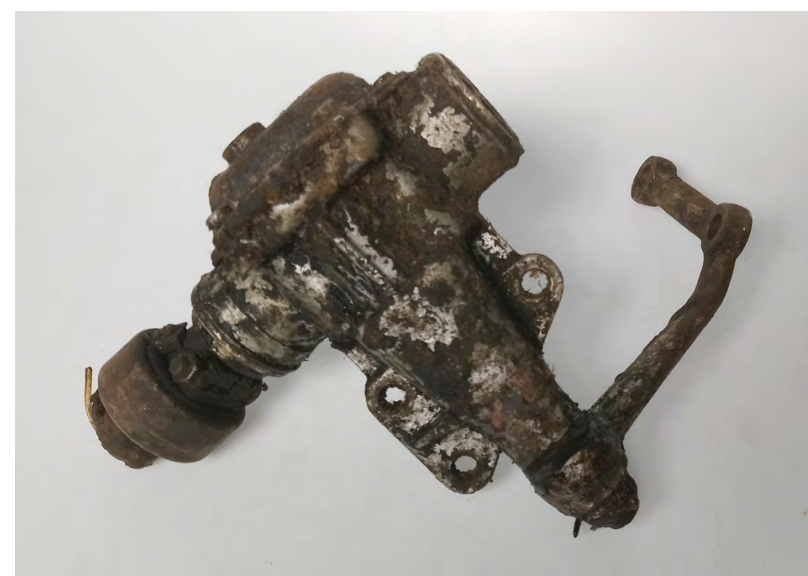

Fig. 1. Impurities on the object used for the experiment of a mesh size of $200 \mu \mathrm{m}$. Followingly, surgical spirit was evaporated from the solution and there remained fine viscous substance. The substance was applied to the testing coupons by spreading with a swab into a thin even layer.

\section{The cleaning procedure and the evaluation method}

When evaluating the efficiency of the cleaning baths, the impact of parameters as the cleaning time $(5,15$ and $30 \mathrm{~min})$, the bath temperature $\left(25\right.$ and $\left.50{ }^{\circ} \mathrm{C}\right)$, and the cleaning frequency $(20$ and $40 \mathrm{kHz}$ ) was observed. For the experiment was used an ultrasound cleaner DSA-LS 600-GL1. The mentioned parameters could be modified at the cleaner. The evaluation was made on the one hand based on the photo documentation, on the other hand based on the weight-loss of the impurities. The photo documentation was captured also in UV light because the not removed impurities showed a fluorescence in it [2].

\section{Weight-loss method}

The measurement of weight-loss was carried out in the following way. Firstly, the clean coupons (a set of $10 \mathrm{pcs}$ ) degreased with surgical spirit were weighed on an analytical balance. Followingly, the coupons after the applying of a layer with impurities were weighed and finally, they were weighed after the cleaning and drying. The result was the percentage of removed impurities. Since there were big differences between the values in several cases, a median value of the set was chosen as a representative value. If the removal of impurities

Tab. 2. Evaluation of the percentage of removed impurities in the preparation AgMAX III

\begin{tabular}{|c|c|c|c|}
\hline $\begin{array}{c}\text { Cleaning } \\
\text { frequency } \\
\text { [kHz] }\end{array}$ & $\begin{array}{c}\text { Temperature } \\
{\left[{ }^{\circ} \mathrm{C}\right]}\end{array}$ & $\begin{array}{l}\text { Time } \\
\text { [min] }\end{array}$ & $\begin{array}{c}\text { Median value of } \\
\text { removed impurities } \\
{[\%]}\end{array}$ \\
\hline \multirow{6}{*}{40} & \multirow{3}{*}{25} & 5 & 60 \\
\hline & & 15 & 92 \\
\hline & & 30 & 100 \\
\hline & \multirow{3}{*}{50} & 5 & 100 \\
\hline & & 15 & - \\
\hline & & 30 & - \\
\hline \multirow{6}{*}{20} & \multirow{3}{*}{25} & 5 & 95 \\
\hline & & 15 & 100 \\
\hline & & 30 & - \\
\hline & \multirow{3}{*}{50} & 5 & 96 \\
\hline & & 15 & 100 \\
\hline & & 30 & - \\
\hline
\end{tabular}


Tab. 3. Evaluation of the percentage of removed impurities in the preparation Star BN S

\begin{tabular}{|c|c|c|c|}
\hline $\begin{array}{l}\text { Cleaning } \\
\text { frequency } \\
\text { [kHz] }\end{array}$ & $\begin{array}{c}\text { Temperature } \\
{\left[{ }^{\circ} \mathrm{C}\right]}\end{array}$ & $\begin{array}{l}\text { Time } \\
\text { [min] }\end{array}$ & $\begin{array}{c}\text { Median value of } \\
\text { removed impurities } \\
{[\%]}\end{array}$ \\
\hline \multirow{6}{*}{40} & \multirow{3}{*}{25} & 5 & 28 \\
\hline & & 15 & 40 \\
\hline & & 30 & 35 \\
\hline & \multirow{3}{*}{50} & 5 & 88 \\
\hline & & 15 & 91 \\
\hline & & 30 & 99 \\
\hline \multirow{6}{*}{20} & \multirow{3}{*}{25} & 5 & 41 \\
\hline & & 15 & 88 \\
\hline & & 30 & 93 \\
\hline & \multirow{3}{*}{50} & 5 & 93 \\
\hline & & 15 & 96 \\
\hline & & 30 & 96 \\
\hline
\end{tabular}

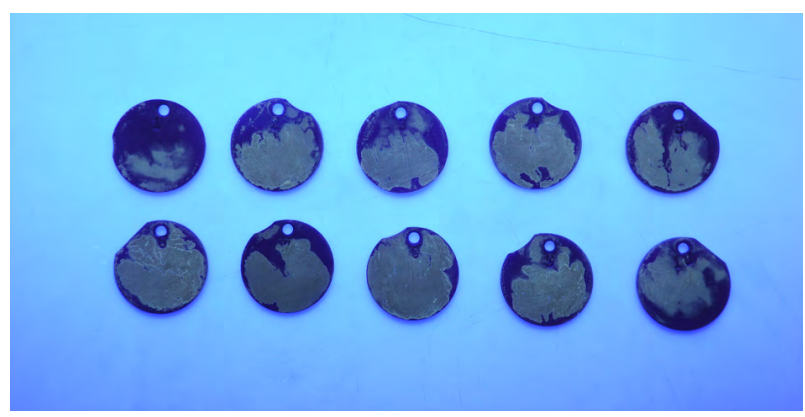

Fig. 2. Samples after cleaning in the solution Ag MAX III

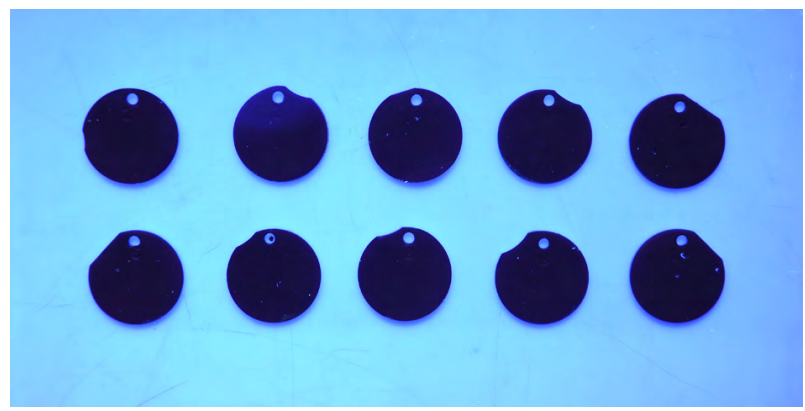

Fig. 3. Samples after cleaning in the solution Star TN

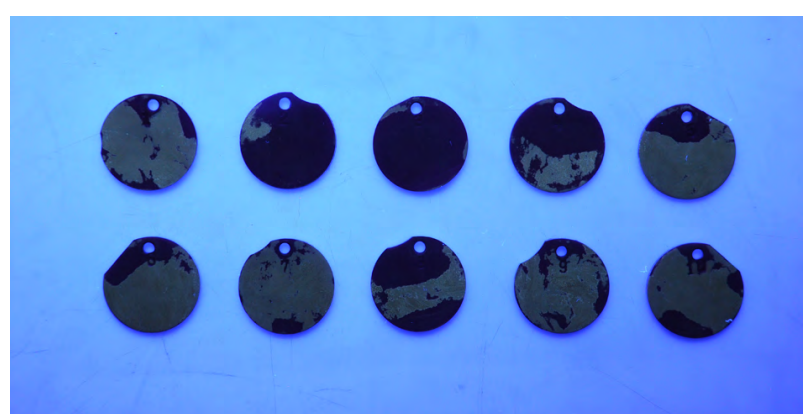

Fig. 4. Samples after cleaning in the solution Star BS N was in one time $100 \%$, then the experiment was not carried out in the longer time anymore (it is marked with a dash in Tab. 2). The values of the percentage of removed impurities are summarized in Tab. 2 and 3. In these tables, there are only preparations AgMAX III and Star BS N, because in the preparation Star TN, 100\% removing of impurities occurred just after 5 minutes under all cleaning conditions. In Figures 2-4, there are documented the samples in UV light after the cleaning in the solutions after 5 minutes at a temperature of $25^{\circ} \mathrm{C}$ and a frequency of $40 \mathrm{kHz}$. The light spots on the photographs mark the not removed impurities. [2]

\section{Surface tension - measuring of contact angle}

Another factor for observing the efficiency of cleaning baths was the measuring of contact angle of a water drop (with added blue ink for a better contrast) on the surface of the subject to be cleaned. The contact angle gives the wettability rate of the surface for a liquid (here for water). The smaller the angle is, the higher is the wettability. By this experiment it was discovered how the given preparations change the surface tension. For this experiment, the aluminium coupons were divided into three sets of 3 pieces according to the solutions. Firstly, they were degreased with surgical spirit and the contact angle was measured (on each coupon 3 times). After that, they were left in the cleaner in the $20 \%$ solutions of concentrates for 15 minutes at a temperature of $25^{\circ} \mathrm{C}$ and a frequency of $40 \mathrm{kHz}$. After taking them out of the bath, they were washed with demineralized water, dried on the air and the contact angle was measured again. The change of the contact angle is summarized in Table 4, an illustration of the measuring is in the Figures 5 and 6. For the measuring was used the device See system 7.0 from the company Advex Instruments. [3]

Tab. 4. The change of contact angle after the impact of cleaning solutions

\begin{tabular}{|c|c|c|c|}
\hline $\begin{array}{c}\text { Cleaning } \\
\text { solution }\end{array}$ & Coupon & $\begin{array}{c}\text { Starting } \\
\text { contact } \\
\text { angle [ }{ }^{\circ} \text { ] }\end{array}$ & $\begin{array}{c}\text { Contact angle } \\
\text { after the action of } \\
\text { the solution [ }{ }^{\circ} \text { ] }\end{array}$ \\
\hline \multirow{3}{*}{$20 \%$ AgMAX III } & 1 & 80 & \multirow{2}{*}{ Non-measurable* } \\
\cline { 2 - 3 } & 2 & 89 & \\
\hline \multirow{2}{*}{$20 \%$ Star TN } & 4 & 79 & \multirow{2}{*}{ Non-measurable } \\
\cline { 2 - 3 } & 5 & 81 & \\
\cline { 2 - 3 } & 6 & 87 & 53 \\
\hline \multirow{3}{*}{$20 \%$ Star BS N } & 7 & 81 & 49 \\
\cline { 2 - 3 } & 8 & 85 & 61 \\
\cline { 2 - 3 } & 9 & 82 & 53 \\
\hline
\end{tabular}

* The term non-measurable means that the drop of water with ink spilled completely on the surface, thus the contact angle was close to $0^{\circ}$. However, it was not possible to measure it. 


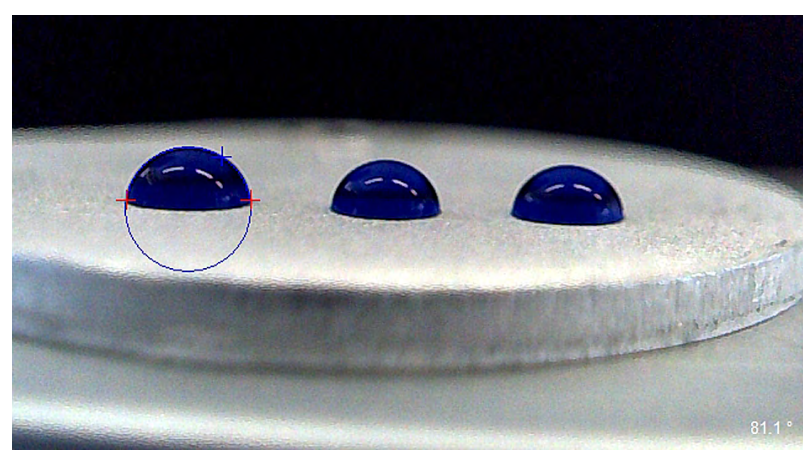

Fig. 5. Measuring of the starting contact angle (coupon no. 9)

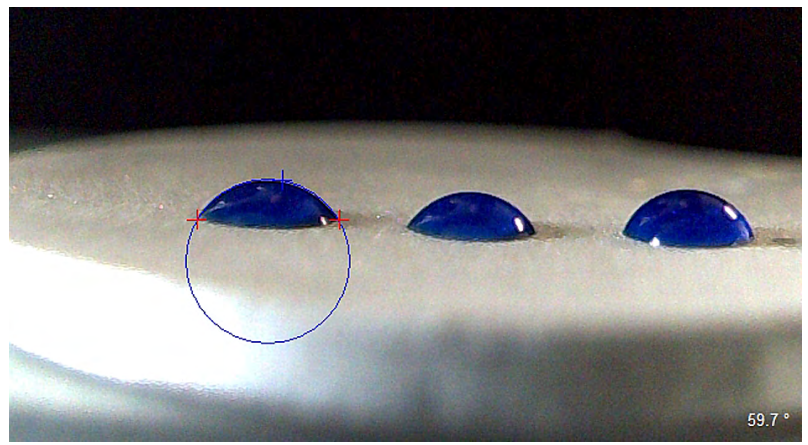

Fig. 6. Measuring of the contact angle after the impact of the concentrate Star BS N (coupon no. 9)

\section{Determination of dissolved metals}

The efficiency of cleaning solutions can go together with their higher aggressivity for the material. Since the $\mathrm{pH}$ of the selected metals was in the alkaline range, a possible dissolution of amphoteric metals, such as e. $\mathrm{g}$. aluminium or zinc can be assumed. As regards the cleaning of the components of historical vehicles and motorcycles, most frequently it will be about alloys of zinc, aluminium, copper, and iron. That is why it was observed during the study to which extent they are being released into the solution during the cleaning procedure.
For this experiment were prepared metal coupons of $\mathrm{Zn}$, $\mathrm{Al}, \mathrm{Cu}$ and $\mathrm{Fe}$ of a size of $1 \times 1 \mathrm{~cm}$. These were put one by one into bowls with $20 \mathrm{~cm}^{3}$ of $20 \%$ cleaning solutions. They were left in the ultrasound cleaner for 1 hour at a temperature of $50{ }^{\circ} \mathrm{C}$ and an ultrasound frequency of $20 \mathrm{kHz}$. Afterwards, the amount of metals dissolved in the solutions was determined by atomic absorption spectrometry with electrothermal atomic absorption (ET AAS). For the analysis was used atomic absorption spectrometer ContrAA 800 G (manufacturer - Analytik Jena) with a graphite cuvette. The advantage of a graphite cuvette is the fact that the matrix (in this case the cleaning solutions) evaporates after the heating-up and does not influence the results of the analysis. Since precipitates developed in some solutions, they were resuspended in an ultrasound bath and the sample was filtered by means of ultrafiltration tubes Corning Spin-X (the size of pores of $0,22 \mu \mathrm{m}$ ). The determined content of metals in the solutions is summarized in Table 5. In Table 6 , the values of dissolved metal ions are converted into corrosion rate in millimetres per year.

\section{Mechanical impact of ultrasound on defects}

During the impact of ultrasound on the surface, which is to be cleaned, beatings develop due to the cavitation of the cleaning preparation. The beatings impact mechanically on the surface. Because of this, the impurities are effectively being removed, but also mechanical damage of the object can occur. In components of historical vehicles can develop cracks due to corrosion or mechanical stress. An experiment was prepared to observe the impact of ultrasound on defects. The tested material were two aluminium coupons which were bent in such a way as to develop a crack. Each coupon was then left for 1 hour in the cleaner with demineralized water. One of them was exposed to the activity of ultrasound of a frequency of $20 \mathrm{kHz}$, the second one to a frequency of $40 \mathrm{kHz}$. The evaluation was carried out by

Tab. 5. The content of metals in cleaning solutions determined by ET AAS

\begin{tabular}{|c|c|c|c|c|}
\hline Solution & Content of Al [ppm] & Content of Zn [ppm] & Content of Cu [ppm] & Content of Fe [ppm] \\
\hline Ag MAX III & $0,20 \pm 0,01$ & $36,3 \pm 1,40$ & $4,20 \pm 0,05$ & $0,080 \pm 0,003$ \\
\hline Star TN & $0,16 \pm 0,03$ & $33,2 \pm 0,20$ & $5,8 \pm 0,1$ & $0,050 \pm 0,005$ \\
\hline Star BS N & $4,06 \pm 0,30$ & $2,1 \pm 0,1$ & $0,14 \pm 0,02$ & $0,050 \pm 0,001$ \\
\hline
\end{tabular}

Tab. 6. Corrosion rate of metals in cleaning solutions

\begin{tabular}{|c|c|c|c|c|}
\hline Solution & $\mathbf{v}_{\text {corr }}(\mathbf{A l})[\mathbf{m m} / \mathbf{a}]$ & $\mathbf{v}_{\text {corr }}(\mathbf{Z n})[\mathbf{m m} / \mathbf{a}]$ & $\mathbf{v}_{\text {corr }}(\mathbf{C u})[\mathbf{m m} / \mathbf{a}]$ & $\mathbf{v}_{\text {corr }}(\mathbf{F e})[\mathbf{m m} / \mathbf{a}]$ \\
\hline Ag MAX III & 0,064 & 4,5 & 0,41 & 0,0089 \\
\hline Star TN & 0,052 & 4,1 & 0,57 & 0,0056 \\
\hline Star BS N & 1,3 & 0,26 & 0,014 & 0,0056 \\
\hline
\end{tabular}


microscopic photo documentation of the cracks, before and after the impact of ultrasound. The lengths and widths of the cracks were measured in the pictures and it was so evaluated if they change. The comparison of the condition before and after ultrasound is documented in Figures 7 and 8 . Based on the comparison of the pictures and measurements, no change of the crack during the cleaning was discovered.

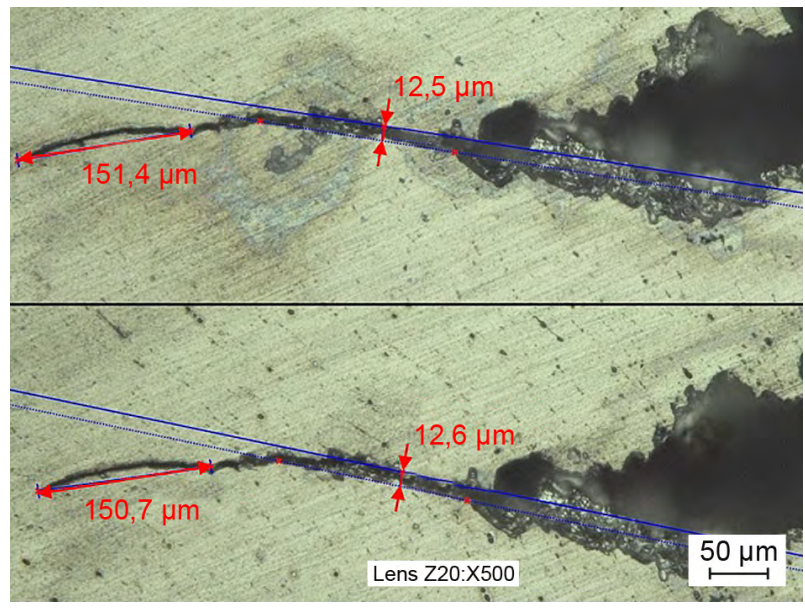

Fig. 7. Comparison of the crack after the exposure to ultrasound of a frequency of $20 \mathrm{kHz}$ (above: before the exposure, below: after the exposure), $500 \times$ magnified

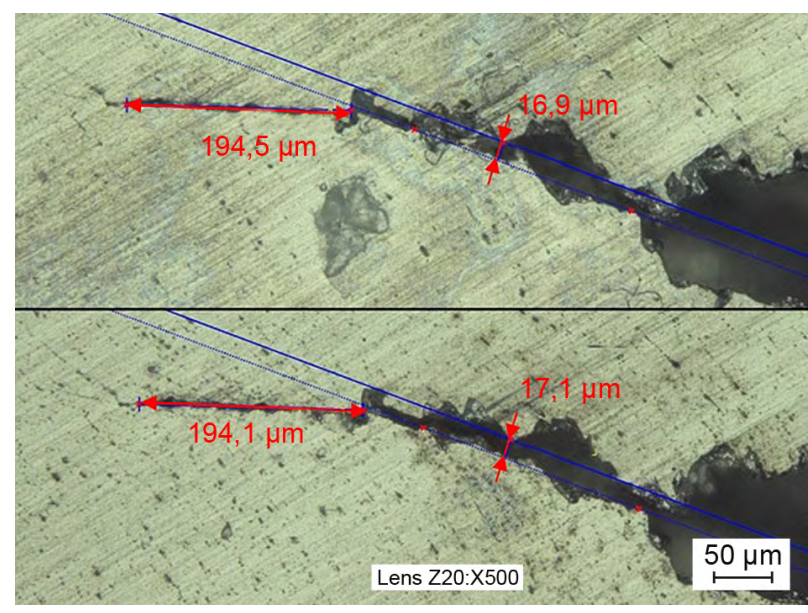

Fig. 8. Comparison of the crack after the exposure to ultrasound of a frequency of $40 \mathrm{kHz}$ (above: before the exposure, below: after the exposure), $500 \times$ magnified

\section{Ultrasonic cleaning in practice}

To examine the above tested procedures of ultrasonic cleaning in practice, 3 parts of historical motorcycles of aluminium alloy were chosen. They were fouled in some places with large deposits of dried oil with dust. Each component was cleaned in a different solution under the same conditions. Given that the fouling was extensive, the following conditions were chosen: 60 minutes in a $20 \%$ bath at a temperature of $50{ }^{\circ} \mathrm{C}$, an ultrasound frequency of $20 \mathrm{kHz}$, and a maximum power of the cleaner. After the objects were taken out of the bath, they were washed with water and the impurities which do not adhere to the surface were removed with a small brush. The comparison of the results before and after the cleaning is documented in the detail in Figures 9-11. Finally, the same procedure was applied with the preparation AgMAX III to clean the carburettor Jikov 40 SOP from a historical vehicle Praga $\mathrm{RN}$ (year of manufacture 1952, Fig. 12). The efficiency of the cleaning can be seen in Figures 13 and 14.

\section{EVALUATION OF EXPERIMENTS}

The ultrasonic cleaning is an effective method to remove the deposits of impurities. Compared to other methods of mechanical cleaning, ultrasound impacts the whole surface of an object inclusive cavities. This is a great advantage for the cleaning of car components, such as e. g. carburettors, where also the passages can be cleaned. The influence of the cleaning parameters (bath temperature, cleaning time, and ultrasound frequency) and the efficiency of cleaning concentrates were observed within the experiment. As regards the cleaning parameters, the efficiency logically increased with the temperature and the cleaning time. Further, it is also confirmed that a lower ultrasound frequency impacts the surface more significantly, thus it cleans the surface better. $[1,4]$

The removing of oily impurities reflected the impact of the $\mathrm{pH}$ of selected solutions. From the results follows that the more alkaline is the solution, the more effective it is. In the preparation Star TN with $\mathrm{pH}=11,97$ was observed a $100 \%$ efficiency already after 5 minutes of cleaning under various combinations of other parameters (time and temperature). On the contrary, the lowest efficiency had the preparation Star BS N, which follows from the weight-loss on the one hand, and on the other hand from the contact angle which was $54^{\circ}$ on average. The contact angle was non-measurable at other solutions due to a high wettability of the surface. It can be judged that it was close to $0^{\circ}$. The gentle impact of the cleaning concentrates on the selected metals ( $\mathrm{Al}, \mathrm{Zn}, \mathrm{Cu}$ and $\mathrm{Fe}$ ) was discovered by a determination of dissolved ions in the solutions after a one-hour exposition to ultrasound using atomic absorption spectrometry. It was found (according to Tabs. 5 and 6) that mostly, a dissolution of zinc takes place in the order of tens ppm (which is equivalent to the corrosion rate in ones $\mathrm{mm} / \mathrm{year}$ ), the least, a dissolution of iron takes place where the concentration was 3 orders lower. Among the selected solutions, the lowest determined concentrations were in the preparation Star BS N, except for the content of aluminium which was one order higher than in the other solutions. On the other hand, the efficiency of the 
preparation Star BS $\mathrm{N}$ in removing of impurities was the lowest. The content of metal ions in the other two solutions was nearly the same.

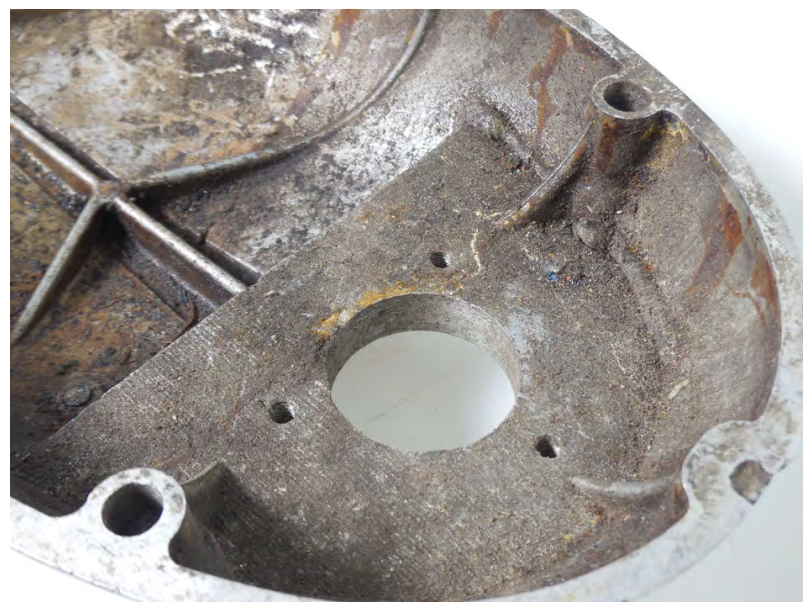

a)

Fig. 9. Object A before (a) and after (b) cleaning (Ag MAX III)

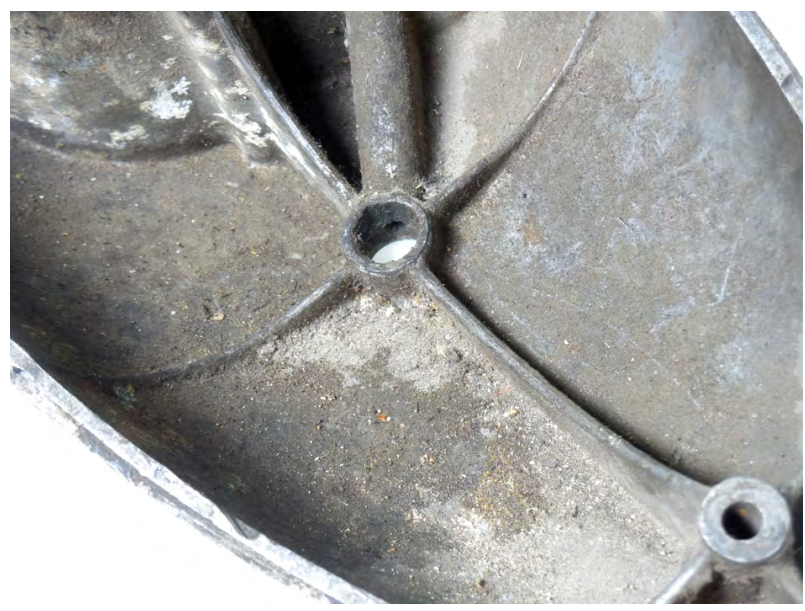

a)

Fig. 10. Object B before (a) and after (b) cleaning (Star TN)

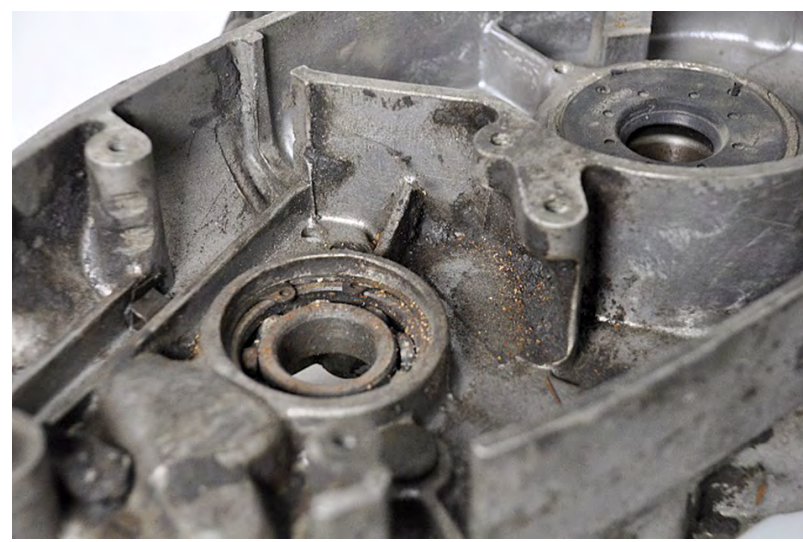

a)
A mechanical impact of ultrasound on defects in the structure was observed at the samples of coupons with cracks. The coupons were exposed to ultrasound

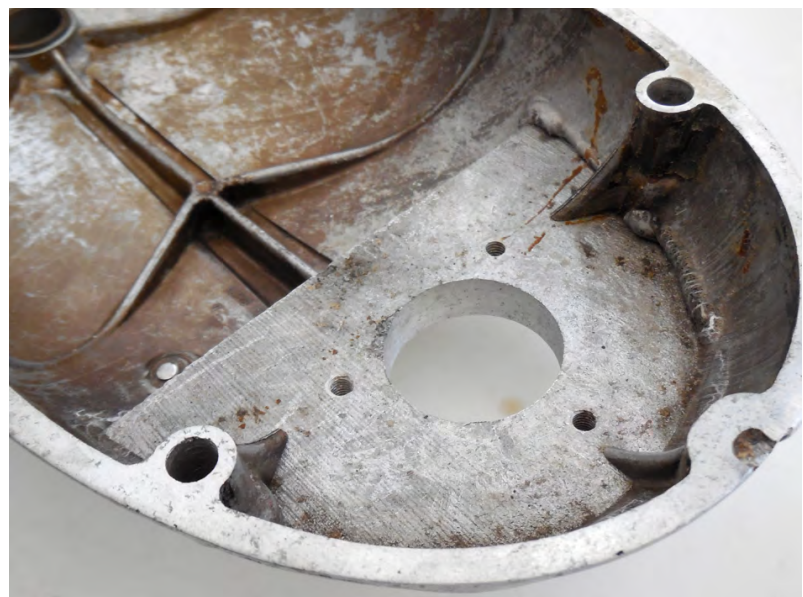

b)

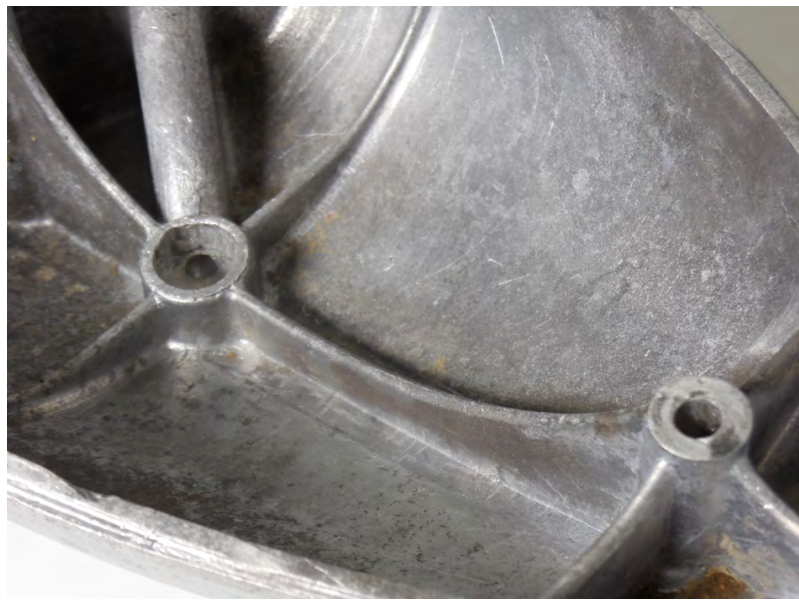

b)

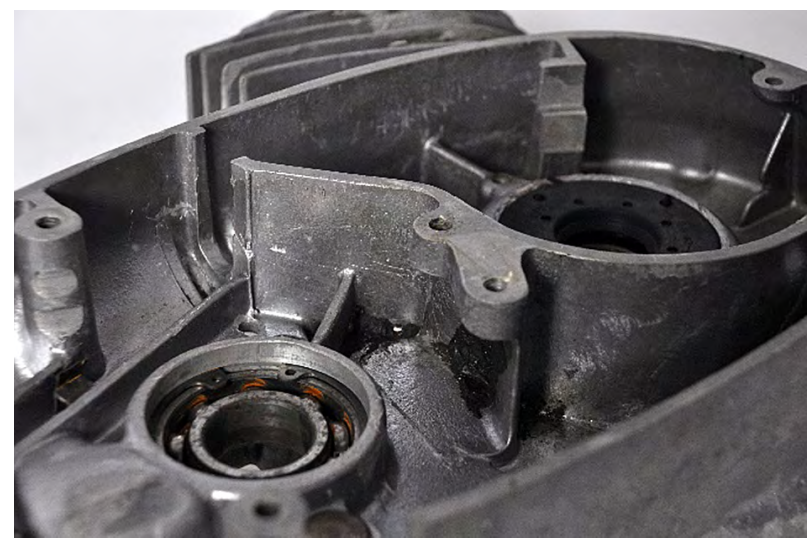

b)

Fig. 11. Object $\mathrm{C}$ before (a) and after (b) cleaning (Star BS N) 
of a frequency of $20 \mathrm{kHz}$ for 1 hour. According to Figures 7 and 8 , neither shape changes nor spreading of cracks occurred during the exposition. However, it was a compact material without corrosion damage. On the contrary, in an object with worse mechanical qualities

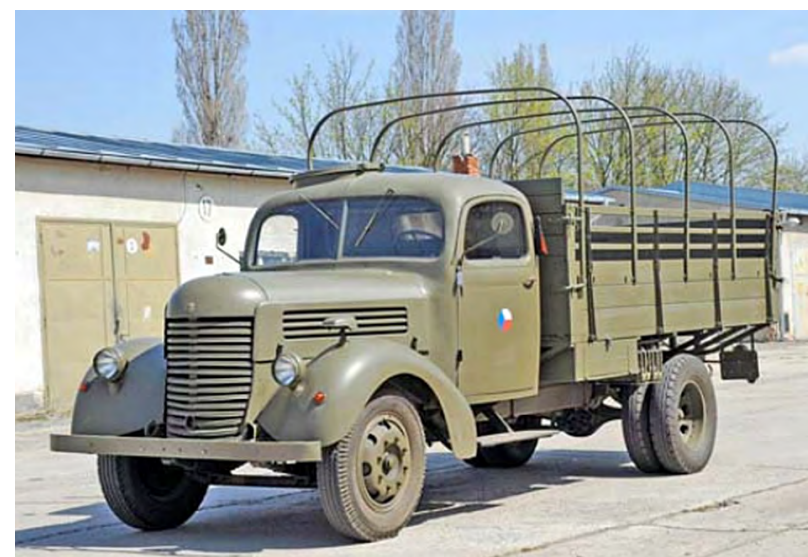

Fig. 12. Platform car Praga RN (photo: Eva Řezáčová)

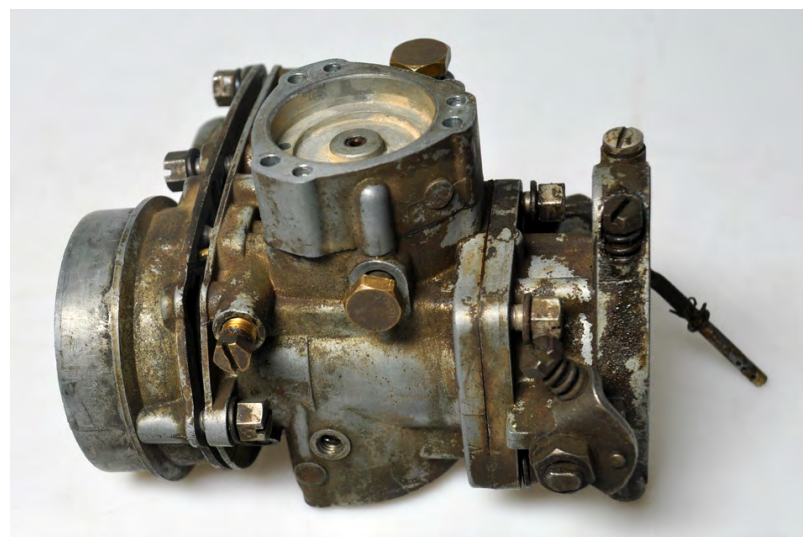

a) and cracks in the microstructure exposed to ultrasound could the defects spread due to the corrosion. When testing the cleaning at real objects, the results were comparable. Only in case of the preparation Star BS N, the residues of impurities are more visible in some places.

\section{CONCLUSION}

The use of ultrasonic waves in cleaning of deposits of impurities and degreasing the surface of components of historical vehicles has several advantages. These are a higher efficiency than in case of manual cleaning, particularly in places which are difficult to access and in cavities, and time saving. When observing the impact of the parameters on the result of the cleaning, it was confirmed, that the efficiency increases with the increasing time of impact and with bath temperature. To remove roughly the impurities, it is more advantageous to use a lower ultrasound frequency. When testing the cleaning concentrates, it was found that their efficiency

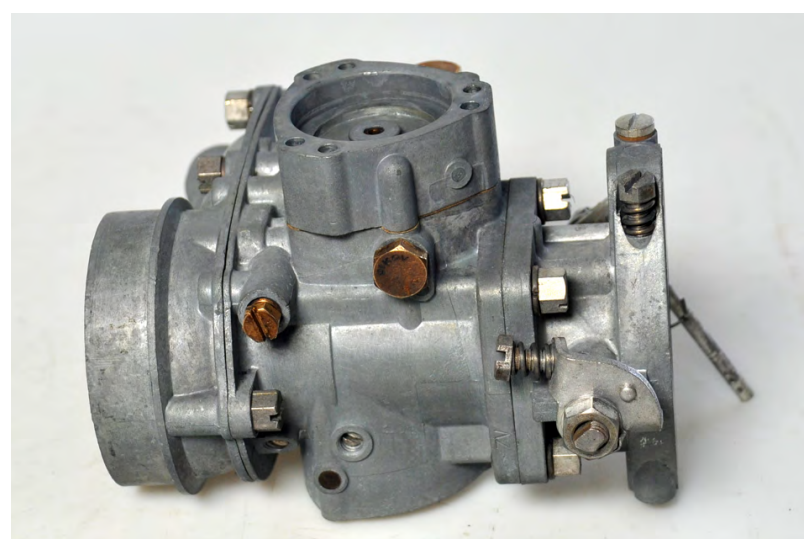

b)

Fig. 13. Carburettor Jikov 40 SOP before (a) and after (b) cleaning

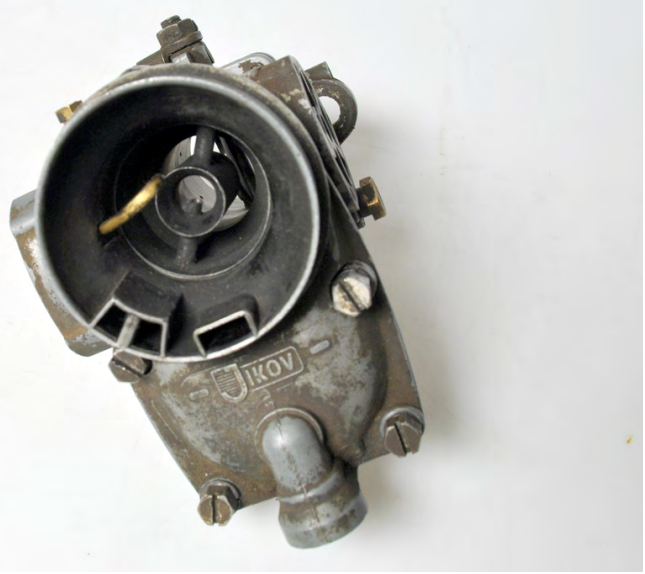

a)

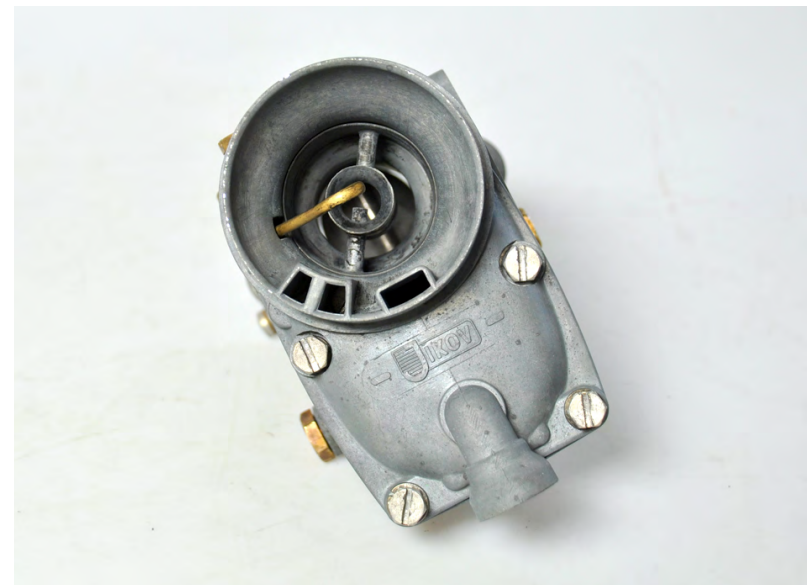

b)

Fig. 14. Carburettor Jikov 40 SOP - injection chamber before (a) and after (b) cleaning 
in removing the grease is connected with their $\mathrm{pH}$. The higher is the $\mathrm{pH}$ value, the better degreased is the surface. On the other hand, the risk of chemical impact on amphoteric metals increases, such as e. g. aluminium or zinc, where a bigger release of ions into the solution takes place. Among the selected preparations, it is most advantageous to use Ag Max III. Its $\mathrm{pH}$ value $=9,41$ lied in the middle of the selected concentrates and it is sufficiently efficient during the practical test (Figs. 9, 13 and 14). The mechanical impact of ultrasound on the defects in the structure was observed by means of microscope. Possible changes of cracks were measured. During the exposition to ultrasonic waves, no cracks spread. However, this need not to be valid for example in corroded objects which are more corroded, and in which develop cracks of the microstructure.

\section{Acknowledgement}

This work was supported and created as a partial output within the Institutional Support of Long-Term Conceptual Development of the Research Organization of the Technical Museum in Brno. Hereby I would like to thank RNDr. Ondřej Zverrina, Ph.D. for the optimization of the procedure and for the evaluation of the dissolved metal ions by ET AAS method.

\section{REFERENCES}

1. Conservation unit museum and galleries commission. The Science for Conservators Series: Volume 2: Cleaning. Routledge 2005, p. 136, 0-415-07165-8.

2. Kopřiva, A. Porovnání účinnosti odmašt'ovacích prostředků. Bakalářská práce, České vysoké učení technické v Praze, 30. 6. 2015.

3. Schuster, J. M.; Schvezov, C.; Rosenberger, M. R. Influence of Experimental Variables on the Measure of Contact Angle in Metals Using the Sessile Drop Method. Procedia Materials Science [Online] 2015, 8, 742-751. https://www. researchgate.net/publication/279532403_Influence_of Experimental_Variables_on_the_Measure_of_Contact Angle_in_Metals_Using_the_Sessile_Drop_Method/ references (accessed April 13, 2020).

4. Award, S. B. Aqueous and Corrosion Protection of Steel Components. Metal Finishing [Online] 2004, 102, 56-61. https://reader.elsevier.com/reader/sd/pii/S0026057604 846762? token=46B78992B363EDD289C99B024AFEBE 7AB879FA69095B4BC5FC24056112288399C33C698B4 D71D832FE1D98EA2F33570E (accessed April 15, 2020).

5. Kolektiv autorů. Konzervováni a restaurování kovů. Brno: TMB, 2011. ISBN 978-80-86413-70-9. 